This paper highlights the need:

- To improve the assessment of orthodontic treatment need

- To improve the IOTN index by reporting its shortcomings

- To stress the need for incorporation of a measure of oral health-related quality of life in the assessment of orthodontic treatment need

- To reduce inequalities in the provision of orthodontic treatment

\title{
The planning, contracting and monitoring of orthodontic services, and the use of the IOTN index: a survey of consultants in dental public health in the United Kingdom
}

\section{M. de Oliveira ${ }^{1}$}

\begin{abstract}
Objectives To establish which factors are used in planning, contracting and monitoring orthodontic services in the United Kingdom. In addition, the study investigated the value of the Index of Orthodontic Treatment Need (IOTN) as an instrument for planning orthodontic provision.

Methods A structured questionnaire was sent to all consultants in dental public health in the United Kingdom.

Results Over $80 \%$ of the respondents used the Index of Orthodontic Treatment Need (IOTN) as an instrument for planning, contracting and monitoring orthodontic services. Seventy per cent of these consultants regarded the IOTN index as a useful or very useful instrument. The main strength reported was that the IOTN index allows prioritisation (25.0\%). The main weakness reported was that the index does not assess complexity (70.5\%).

Conclusions Consultants in dental public health perceived the IOTN as a useful tool for planning orthodontic provision despite some shortcomings.
\end{abstract}

There are two main objectives for the assessment of occlusion in public health. The first is to screen the population for individual treatment need and priority. The second is to obtain information for the planning of resources and facilities for orthodontic treatment. ${ }^{1}$ During the past few decades there has been an increasing demand for orthodontic treatment in the United Kingdom. For example, in the year ending March 2001, the total number of orthodontic claims for adults and children in England and Wales rose by $5.7 \%$, from 571,713 claims made the previous year, to 604,278 . The total number of orthodontic claims increased each year since the year ending March 1992 when there were 280,349 claims. Of the 604,278 orthodontic claims made in the year ending March 2001, 261,639 (or 43.3 \%) were appliance claims. The

\footnotetext{
${ }^{*}$ Research Fellow, Department of Epidemiology and Public Health, University College London, 1-19 Torrington Place, 3rd Floor, London WC1E 6BT

${ }^{*}$ Correspondence to: Dr Cesar Messias de Oliveira

Email:cmdeoliveira@blueyonder.co.uk
}

\section{Refereed paper}

Received 31.10.02; Accepted 30.06.03

doi:10.1038/sj.bdj.4810833

(c) British Dental Journal 2003; 195: 704-706 ratio of orthodontic claims to appliance claims has increased from 1.5 in 1992 to 2.3 in March 2001. In the year ending March 2001 , the annual expenditure on orthodontic treatment in the general dental service increased by $13.3 \%$ from $£ 85.3$ million the previous year to $£ 96.7$ million. There has been an upward trend for annual expenditure on orthodontic treatment since 1992, increasing by $85.5 \%$ in this 10 -year period. ${ }^{2}$ As a result of the increased demand, waiting lists and waiting times for orthodontic treatment have grown. In the United Kingdom, where orthodontic treatment is provided through the general dental service (GDS), the community dental service (CDS), and the hospital dental service (HDS), there is an uneven regional uptake for treatment, which is strongly related to the distributions of orthodontic manpower.

In response to the increased pressures, indices have been developed which attempt to prioritise need in accordance with the severity of the malocclusions and treatment need. Different examiners report wide variations in the proportion of subjects in need of treatment. ${ }^{3}$ The wide variations reflect a lack of uniform standards for defining deviations that are severe enough to need orthodontic treatment. The main benefit of orthodontic treatment for the patient may be in improved dental aesthetics and psychosocial well-being. ${ }^{4,5}$ Consequently, assessment of orthodontic treatment should include measures of aesthetic impairment and psychosocial need. Surveys carried out in the United Kingdom have reported doubts about the 'validity' of the orthodontic indices used, namely what it purports to measure. ${ }^{6}$ Even today, there are not sufficient reliable data on the functional and psychosocial impacts of malocclusion to allow true scientific validation of indices of orthodontic treatment need. The Index of Orthodontic Treatment Need (IOTN) ${ }^{7}$ has been developed to address some of the issues described above. It represents an important advance in the evolution of orthodontic treatment need indices.

Responsibility for the planning of oral care provision at a local level lies with consultants in dental public health who also need to ensure that current health policy guidelines are met. Consequently, their views of the extent to which an index is useful are important.

The aim of this study was to assess which factors are being used in the planning of orthodontic provision in the United Kingdom. In addition, the study investigated the value of the Index of Ortho- 
dontic Treatment Need (IOTN) as an instrument for planning, contracting and monitoring orthodontic services as perceived by consultants in dental public health in the United Kingdom.

\section{METHODS}

A list of the names and addresses of individuals holding consultant contracts in dental public health was obtained from the British Association for the Study of Community Dentistry (BASCD). Within the United Kingdom there were 62 consultants, twelve of whom were excluded from the study as they held purely academic honorary contracts. Thus, the sample size for this study was 50.

A pilot study was undertaken in order to establish the feasibility of this study and identify any potential problems. The questionnaire was given to consultants in dental public health in London and after completion of the pilot study the wording and order of the questions on the questionnaire were maintained since no problem was detected regarding its clarity and sequence. Therefore, the design of the questionnaire remained the same.

A self-administered postal questionnaire was chosen instead of face-to-face interview because the population of this study was geographically dispersed. Each research pack contained two copies of the questionnaire, an explanatory letter and a stamped addressed envelope. Two copies of the questionnaire were sent, as some consultants could be responsible for more than one health authority. These consultants were asked to complete a questionnaire for each health authority. Consultants who did not respond within the time frame were contacted by phone and if necessary, new questionnaires were sent.

\section{RESULTS}

A total of 47 questionnaires were returned. Since seven of the consultants returned two questionnaires each, the response rate was $80 \%$. Thirty-two per cent of consultants were female and 68\% male. The average length of time since appointment as consultant was 4.5 years.

The consultants were asked to list the three most important factors influencing the contracting process for orthodontic treatment in their respective health authorities. Overall there was agreement about the most important factors, namely, demand (16.4\%), funding (14.8\%) and manpower (13.4\%). Additionally, $11.7 \%$ of the consultants reported that the assessment of orthodontic treatment need was important. However, it was not clear which methodology was used to assess need, and consequently, the extent to which this factor differed from demand. Other factors cited included quality and effectiveness of treatment, health gain and patient satisfaction.

There was considerable variation among consultants concerning knowledge of current clinical activity even within the health authorities for which the consultants were responsible. The majority (88.6\%) had knowledge of the volume of orthodontic treatment carried out within the hospital dental service and the community dental service but were far less clear of activity in the general dental service (GDS). Only 61.4\% knew the volume of activity of general dental practitioners providing orthodontic treatment through the GDS, and even less, the activity of specialists through the GDS. The consultants were also asked whether they knew the volume of orthodontic treatment outside the National Health Service and 95.5\% had no information on that. The factors that consultants used to assess the volume of orthodontic treatment in their health authorities were historical data (38.1\%), waiting list details (23.8\%), epidemiological data (23.8\%), finance reason (2.4\%) and other reasons (11.9\%).

Just over $80 \%$ of consultants used the IOTN index as an instrument for planning, contracting and monitoring orthodontic services. There was a considerable variation in the reported
Table 1 Views of consultants in dental public health on the strengths and weakness of the IOTN index

\begin{tabular}{lrlc}
\hline Strength & $n(\%)$ & Weakness & $n(\%)$ \\
\hline Widely used & $5(11.4)$ & $\begin{array}{l}\text { Does not assess } \\
\text { complexity }\end{array}$ & $31(70.5)$ \\
\hline Objectivity & $5(11.4)$ & Requires training & $3(6.8)$ \\
\hline Prioritisation & $11(25.0)$ & Does not assess demand & $1(2.2)$ \\
\hline Simple/easy/practical & $8(18.2)$ & Others & $9(20.5)$ \\
\hline Others & $13(27.7)$ & & \\
\hline None & $2(4.5)$ & & $44(100)$ \\
\hline Total & $44(100)$ & Total &
\end{tabular}

usefulness of the index. Just over 18\% found the index very useful, 52.6\% as useful and 26.3\% quite useful. Only one individual stated that it was not useful at all (2.6\%).

The main strengths and weaknesses of the IOTN are shown in Table 1. Factors of particular note relating to the strength of IOTN were its ability to prioritise (25\%) and its simplicity of use (18.2\%). Against this, 70.5\% of the consultants considered the fact that the IOTN does not assess complexity of treatment to be a weakness. Only three consultants reported using another index. Of these two used the Peer Assessment Rating (PAR) ${ }^{8}$ index and one used the PAR in conjunction with the IOTN index.

\section{DISCUSSION}

In some European countries, general dentists and orthodontists have been using indices of treatment need to prioritise state-funded orthodontic treatment for children with major irregularities. This approach allows a selective distribution of resources so that the treatment provided would remain both at a high standard and to protect children from the risks of unnecessary treatment.

In practice this approach is an effective way of both determining the volume of orthodontic treatment required and the extent to which a child will or will not receive orthodontic treatment. In the United Kingdom, the development of an Index of Orthodontic Treatment Need (IOTN) by the University of Manchester has provided a relatively objective assessment of need for treatment that may influence long-term health and dental appearance. This index enables individuals to be objectively classified into three groups namely, 'no/slight treatment need', 'moderate treatment need' and 'definite treatment need'.

The findings of the present study showed that the majority of consultants found the Index of Orthodontic Treatment Need (IOTN) 'useful' or 'very useful' as an instrument for planning, contracting and monitoring orthodontic services. This wide use of the IOTN index should lead to greater uniformity throughout the profession and standardisation in the assessment of orthodontic treatment need. This is a key issue in complying with current health policy.

Furthermore, within the context of a public-funded health system, where it is preferable that allocation of resources is based on need rather than demand, the use of the IOTN index will assist those responsible for planning orthodontic services in the United Kingdom. By forming a basis for deciding who should receive treatment at public expense, the use of such an index may also help to reconcile the increasing demand for orthodontic treatment within a framework of finite resources.

In previous surveys carried out in the United Kingdom, doubts were expressed about the validity of the indices used, namely the extent to which the index measures what it purports to measure. ${ }^{6}$ The present study revealed that the majority of the consultants felt that the IOTN index was easy to use, but this may not be the situation for general dental practitioners who may be required to use it to refer patients. 
The majority of the consultants were only using the dental health component of the IOTN in the present study. This could be explained by the fact that treatment categorizations using the dental health component and the aesthetic component can be contradictory, with one component suggesting treatment and the other suggesting no treatment. ${ }^{9}$ Additionally, some studies have found that children gave lower ratings to various features of malocclusion than orthodontists. ${ }^{10}$

The aesthetic component of the IOTN index only assesses the aesthetic component of the malocclusion, and not any other aspect of psychosocial self-perception. It is evident that children's views on appearance are not fully captured by an epidemiological index of need such as the IOTN. ${ }^{11}$ There is a strong case for an additional oral health-related quality of life component. ${ }^{12}$ Generally, such oral health-related quality of life information confers advantages in understanding oral-related behaviour and widening dental evaluation beyond the limits of conventional epidemiological indices. ${ }^{13}$

In the present study, 25\% of the respondents said that one of the strengths of the IOTN index is that it allows prioritisation. Scores of 4 or 5 in the dental health component of the IOTN index indicate a need for treatment independent of the aesthetics of the case. Conversely, scores of 1 and 2 do not constitute treatment need. The difficulty arises for those children with a dental health component score of 3. In this situation the use of the aesthetic component comes into play, particularly for children with a poor awareness of their own oral appearance.

Over the past decade there has been a general rise in the expectations and aspirations of people regarding their dental appearance. As a result, the demand for orthodontic treatment has increased. Furthermore, in many parts of the United Kingdom there are long waiting lists for hospital orthodontic treatment. This is a matter of considerable concern in public health and for policy makers. In addition, the results from a study conducted by Kisely et al. ${ }^{14}$ suggested that the delivery of care is neither based on objective need nor on equitable distribution. More appropriate directing of resources is required, using the IOTN and agreed protocols, so that referrals are made to the most suitable provider. It is essential, therefore, that health authorities carefully prioritise and plan the provision of orthodontic treatment. The introduction of valid and reliable indices of therapeutic need such as the Index of Orthodontic Treatment Need (IOTN) will allow improved focusing of services.

As many as $70.5 \%$ of the consultants in dental public health reported that one of the weaknesses of the IOTN index was the fact that it does not measure complexity of treatment required. It was stated that some patients within Grade 5 could be treated relatively easily, while others, in Grade 3, might be technically more difficult and time consuming to treat. This finding is supported by the conclusions of Willmot et al. ${ }^{15}$ where 'urgency' and 'complexity' were used more frequently than orthodontic indices as a guide to placing patients on waiting lists. Ideally, orthodontic consultants would treat only patients with malocclusions requiring the most complex and difficult treatment. Suitably qualified practitioners could treat the remainder within the general dental service and the community dental service. However, it must be made clear to purchasers that the IOTN is a clinical tool and that the interpretation of the information it provides is for the clinician. The IOTN should support clinical judgement and not replace it. Furthermore, it is unlikely that one orthodontic treatment need index alone can satisfy all the criteria for patient selection.

\section{CONCLUSIONS}

Any public health policy to provide orthodontic treatment requires accurate information on resources in order to cope with treatment load, level of clinical skills required, time, training, assistance, equipment, and facilities. This can only be done through good knowledge of the size and nature of the problem. Until a standardised approach to objectively assess orthodontic treatment need is accepted and used by both the profession and the receivers of treatment, the provision of care and ensuing imbalance between need and demand for orthodontic treatment will remain unequal. Consultants in dental public health perceived the IOTN as a useful tool for planning orthodontic provision for the population despite existing weaknesses.

The author is grateful to the Fundação Coordenação de Aperfeiçoamento de Pessoal de Nivel Superior (CAPES), Brazilian Government, for their financial support.

1. Foster TD, Menezes D M. The assessment of occlusal features for public health planning purposes. Am J Orthod 1976; 69: 83-90

2. Dental Practice Board Orthodontics. General Dental Service Annual Statistics April 2000 - March 2001. Dental Data Services, Dental Practice Board, England and Wales, July 2002.

3. Downer M C. Craniofacial anomalies - are they a public health problem? Int Dent J 1987: 37: 193-196.

4. Shaw W C, Gabe M J, Jones B M. The expectations of orthodontic patients in South Wales and St. Louis, Missouri. Br J Orthod 1980; 7: 75-80.

5. Shaw W C, Addy J, Ray C. Dental and social effects of malocclusion and effectiveness of orthodontic treatment: A review. Community Dent Oral Epidemio/ 1980; 8: 36-45.

6. Foster T D. Orthodontic surveys - a critical appraisal. Br J Orthod 1980; 7: 59-63.

7. Brook P H, Shaw W C. The development of an orthodontic priority index. Eur J Orthod 1989; 11: 309-320.

8. Richmond S, Shaw W C, Stephens CD, O'Brien K D, Buchanan I B, Jones R, Roberts C T, Andrews M. The development of the PAR Index (Peer Assessment Rating), reliability and validity. Eur J Orthod 1992; 14: 125-139.

9. Daniels $C_{1}$ Richmond $S$. The development of the index of complexity, outcome and need (ICON). J Orthod 2000; 27: 149-162.

10. Abdullah M S B, Rock W P. Perceptions of dental appearance using Index of Treatment Need (Aesthetic Component) assessments. Community Dent Health 2002; 19: 161-165.

11. de Oliveira C M, Sheiham A. The relationship between normative orthodontic treatment need and oral health-related quality of life. Community Dent Oral Epidemiol 2003 (In Press).

12. Sheiham A, Maizels J E, Cushing A M. The concept of need in dental care. Int Dent J 1982; 32: 265-270.

13. Slade G D, Spencer A J. Development and evaluation of the Oral Health Impact Profile. Community Dent Health 1994; 11:3-11.

14. Kisely S, Howell K, Green J. Pathways to orthodontic care. J Public Health Med 1997; 19: 148-155.

15. Willmot D R, Dibiase D, Birnie D J, Heesterman R A. The Consultant Orthodontists Group survey of hospital waiting lists and treated cases. Br J Orthod 1995; 22: 53-57. 